\title{
Missing Amplification Effect: Focusing Missing Leads to Low Happiness Experience
}

\author{
Tan Fei \\ Jinan University, Guangzhou, China \\ Email: 1253887424@qq.com
}

Received 20 November 2015; accepted 28 December 2015; published 31 December 2015

Copyright (C) 2015 by author and Scientific Research Publishing Inc.

This work is licensed under the Creative Commons Attribution International License (CC BY).

http://creativecommons.org/licenses/by/4.0/

c) (i) Open Access

\begin{abstract}
Prospect theory study found that people's perception of the loss was greater than the strength obtained (Kahneman \& Tversky, 1979), and the cognitive processes of "priority processing trend of negative events" thought that negative events would be priority processing than positive events (Huang \& Luo, 2009). Researchers infer that when people focus on the lack of real life, it will produce the missing amplification effect, and this will further affect people's well-being experiences. We used three experiments to test our hypotheses. Experiment 1 was between subjects design, and found that focusing missing was widespread, in addition, focusing missing and happy experience were negative correlation; Experiment 2 was picture experiment, and found that "missing amplification effect" existed. The greater the missing amplified effect, the lower the happiness; Experiment 3 merged experiment 1 and experiment 2 , And found that the intermediary role between focusing missing and happy experience. Through the above three experiments, we concluded that: focusing missing leaded low happy experience, and missing amplification effect was the psychological mechanisms to explain why the focusing missing leaded to the low happy experience.
\end{abstract}

\section{Keywords}

Experienced Happiness, Focusing Illusion, Focusing Missing, Missing Amplification Effect

\section{Introduction}

Studies found that people would focus what they didn't have and the scarce resource (Shah, Mullainathan, \& Shafir, 2012). For example, people in a state of starvation or thirsty are easier to focus on the food and drink-related clues (Radel \& Clement-Guillotin, 2012), and poor people will focus on the things about money (Shah et al., 2012). The same, when people consider the impact of any single factor on their well-being, they are prone to exaggerate its importance. We refer to this tendency as the focusing illusion (Schkade \& Kahneman, 
1998; Wilson, Wheatley, \& Meyers, 2000; Kahneman, Krueger, Schkade, Norbert Schwarz, \& Stone, 2006; Sandberg, 2007). Studies show that whether forecast is positive or negative emotional event, people will have a focusing illusion. However, the impact of focusing on negative events is significantly higher than that of the positive events. Kahneman \& Tversky (1979) proposed the "prospect theory" inference that individual experience of the benefits and losses was asymmetric, for example, to the same $\$ 100$, the pain of losing the money is much heavier than the happiness of obtaining it and the intensity is 2.5 times showed by research (Kahneman \& Tversky, 1979). The individual perception of the missing was deeper, and more sensitive than acquisition (Rozin \& Royzman, 2001; Huang \& Luo, 2009; Demerouti, Bakker, \& Bulters, 2004).

In the real situation of decision-making, people often measure and think about their "getting" or "missing". When people focus on the missing part, they usually give missing greater weight and overestimate the degree of missing. We define this phenomenon as "missing amplification effect". Accordingly, we speculate that when people focus on missing, missing amplification effect will produce, and missing amplification is the impact of the key to influence happiness experience.

Therefore, we suppose that focusing missing leads to low level of current happiness experience, and "missing amplification effect" is the psychological mechanism that interprets the relationship between the focusing missing and the happiness experience.

\section{Hypotheses}

Based on the above analysis, this study will verify the following three assumptions:

Hypothesis 1: In real life, the focusing missing was existed, and focusing missing could lead to low happiness experience.

Hypothesis 2: When people focus on the missing part, People will overestimate the extent of the missing and the weight, thus, produce missing amplification effect.

Hypothesis 3: Missing amplification effect is the intermediary variable between focusing missing and happiness experience, and Missing amplification effect is the psychological mechanisms to explain why the focusing missing lead to the low happiness experience.

Following is the research framework:

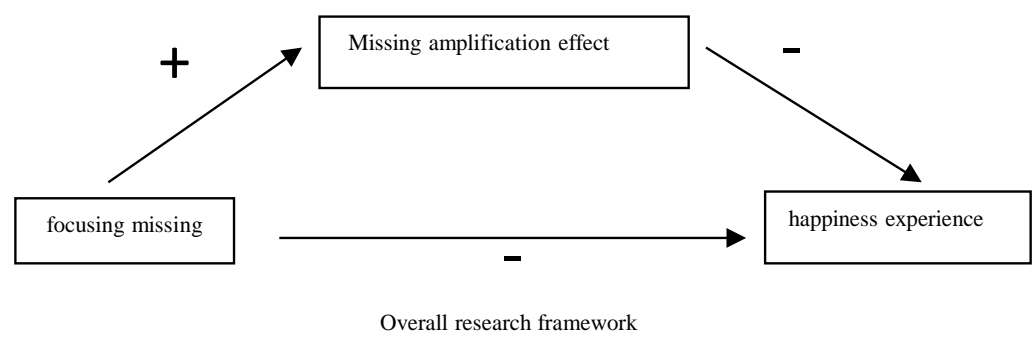

We used three experiments to test our hypothesis. In Experiment 1, the focusing missing and the relationship between the focusing missing and current happiness experience were measured. In Experiment 1, participants were divided into experimental and control groups. The difference between experimental group and control group is that experimental group described the biggest missing in their life, and control group described their favorite scene in their school. Then, we measured the extent of missing and their happy experience. Comparing the actual missing part and the missing part evaluated by participants in experiment 2, we concluded that the distances between actual missing part and evaluated missing part was the missing amplification part. Moreover, Experiment 3 wanted to prove the psychological mechanism of "missing amplification effect". We combined the process of Experiment 1 and Experiment 2.

\section{Studies}

\subsection{Experiment 1}

\subsubsection{Participants}

Participants were college students, total number 112 persons, including 53 boys and 59girls, average age was 
$21.38 \pm 0.61$, all participants were healthy.

\subsubsection{Experimental Materials}

Experimental materials were description of missing events and non-missing events in life. Missing events refers to what people cannot have or have not been able to achieve goals. Non-missing events refers to have things or the goal has been reached.

The item of missing event was "Do you think what is your biggest missing in your life? Please write out in details within 15 minutes". Non-missing events was "Please describe a scene of your university. Please write out in details within 15 minutes". After that, would have a check question "Do you feel missing now?”. Participants needed to answer "Yes" or "No" and evaluated their missing degree ( 1 = non-missing, 9 = very missing).

\subsubsection{Procedures}

At the start of the experiment, all participants were measured happiness experience, which referred to as the pre-test experimental data. The measure tools were Gallup Happy Mood Questionnaire and Life Satisfaction Scale (Diener, Emmons, Larsen, \& Griffin, 1985). Gallup Happy Mood Questionnaire includes three positive emotions (Pleasant, comfortable and fun) and three negative emotions (Anxiety, sadness and stress). Participants needed to do the strength evaluation $(1=$ Very slight, 7 = Very large). Life Satisfaction Scales include five items, for example: "If you can live it again, I would also like have now lives." $(1=$ Strongly Disagree, 7 = Strongly Agree). The Cranach ( $\alpha$ coefficient) of the scale in the study was 0.91 .

Then, participants were divided two groups. One group was experiment group, which described the missing events. The other group was control group, which described the non-missing events.

At the end, all participants were measured happiness experience again, which referred to as the post-test experimental data. The measure tools were the same, Gallup Happy Mood Questionnaire and Life Satisfaction Scale.

\subsubsection{Results}

After t-test for independent samples, about the pre-test experimental data, there was no difference between the experimental group and the control group, description Grouping is effective. However, the missing degree scores of the experimental group $(4.75 \pm 1.28)$ was higher than control group $(3.48 \pm 1.80)$ significantly, $t(110)$ $=4.28, p<0.001$, which proved experimental manipulation effectively.

For experimental group, after Paired sample $\mathrm{T}$ test about the pre-test experimental data and the post-test experimental data. We found that, about Life Satisfaction Scales, the post-test data $(4.08 \pm 0.98)$ was lower than the pre-test data (4.35 \pm 1.01$), t(55)=2.84, p<0.01$, significantly. About Gallup Happy Mood Questionnaire, post-test positive emotion (4.48 \pm 1.44$)$ was lower pre-test positive emotion $(4.68 \pm 01.40), t(55)=2.25, p<$ 0.05 , significantly. Post-test negative emotion $(3.94 \pm 0.96)$ was higher than pre-test negative emotion (3.58 \pm 1.08), $t(55)=-2.80, p<0.05$, significantly.

For control group, after Paired sample $\mathrm{T}$ test about the pre-test experimental data and the post-test experimental data. We found that there was no difference between the post-test data and the pre-test data.

Experiment 1 showed that the happiness experience of experimental group were lower than that of control group, which meant that "focusing missing" negatively predicted individual happiness experience.

\subsection{Experiment 2}

\subsubsection{Participants}

Participants were postgraduate, total number 84 persons, including 40 boys and 44 girls, average age was 23.55 \pm 0.87 , and all participants were healthy.

\subsubsection{Experimental Materials}

Experimental material includes shaded area estimation and estimates the missing area two kinds. In shaded area estimation, participants would see a hollow circle that $\mathrm{O}$ is the center and the diameter is $4 \mathrm{~cm}$. Intercept solid segments sector on the circle, the sector was the shaded area that participants needed to evaluate, referred to as the sector estimated area data. The actual area of the sector was stable, referred to as the sector actual area data (for example, Figure 1). 


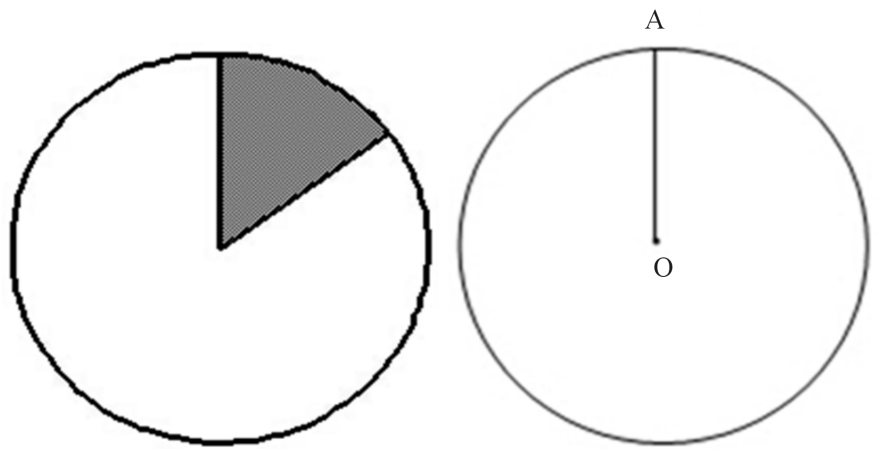

Figure 1. Examples experimental material.

In missing area estimation, participants would need to draw their missing area on the hollow circle that $\mathrm{O}$ is the center and the diameter is $4 \mathrm{~cm}$. Then, evaluated the missing area, referred to as the missing estimated area data, and the actual missing area needed measured, referred to as the missing actual area data (for example, Figure 1).

\subsubsection{Procedures}

At the start of the experiment, all participants completed shaded area estimates. The sector actual area was 65\%. However, participants do not know. After that, participants needed to complete missing area estimates. The instruction was "Imagine the following circle represents your life successfully without missing, but life is not perfect. Please think carefully about the missing events in your own life, then, draw your own missing area and evaluate the area".

At the end, all participants were measured happiness experience. The measure tools were the same, Gallup Happy Mood Questionnaire and Life Satisfaction Scale.

\subsubsection{Results}

About the shaded area estimation, there was no difference between the sector estimated area data $(64.29 \% \pm$ $0.05 \%$ ) and the actual area data $(65 \%), t(82)=1.26, p>0.05$. which showed that participants' estimate graphics ability was normal, there is no deviation.

About the missing area estimation, the missing estimated area data $(33.55 \% \pm 0.21 \%)$ was higher the actual missing area $(30.08 \% \pm 0.22 \%), t(82)=-4.32, p<0.05$, significantly. The result showed that participants clearly overestimated their own missing area, which produced the missing amplification effect (Table 1).

Experiment 2 showed that the evaluated missing part was significantly bigger than actual missing part, and proved that "missing amplification effect" existed.

\subsection{Experiment 3}

\subsubsection{Participants}

Participants were college students, total number 87 persons, including 42 boys and 45 girls, average age was $23.33 \pm 2.745$, all participants were healthy.

\subsubsection{Experimental Materials}

Experimental material was the same of experiment 1 and experiment 2. Because the experiment 3 combined experiments 1 and experiments 2 .

\subsubsection{Procedures}

Experiment 3 was divided into three parts, the first part is focusing missing experiments, experimental procedure is the same as in experiment 1 , but there was just experimental group without control group, participants only completed missing events description. The second part is the missing amplification effect experiments, experimental procedure is the same as in experiment 2. The third part is the measuring of happiness experience, The measure tool was the same Gallup Happy Mood Questionnaire and Life Satisfaction Scale. 
Table 1. Paired sample t-test about the missing estimated area data and actual missing area data $(N=84)$.

\begin{tabular}{rccc}
\hline & actual missing $(M \pm S D)$ & estimated area $(M \pm S D)$ & $p$ \\
\hline Sector area & $65 \% \pm 0.00 \%$ & $64.29 \% \pm 0.05 \%$ & 0.211 \\
Missing area & $30.08 \% \pm 0.22 \%$ & $33.55 \% \pm 0.21 \%$ & $0.000^{* * *}$ \\
\hline
\end{tabular}

Note: ${ }^{* * *} p<0.001$.

\subsubsection{Results}

Participants’ Missing degree as independent variable, Life satisfaction, positive emotions and negative emotions were the dependent variables respectively, missing evaluation area was the mediating variables. Referring Preacher \& Hayes (2004) and Hayes (2013) proposed Bootstrap methods for mediating effect test, Sample chooses 5000, at the 95\% confidence interval, results showed that when life satisfaction was the dependent variables, The mediating effect results did not include 0 (LLCI $=-4.22$, ULCI $=-5.93$ ), explained that intermediary role of missing degree was existed. Mediating effect size is -4.21 ; When positive emotion was the dependent variable, the mediating effect results did not include 0 (LLCI $=-3.48$, ULCI $=-0.25$ ); explained that intermediary role of missing degree was existed. Mediating effect size is -0.43 ; When negative emotion was the dependent variable, the mediating effect results did not include 0 (LLCI $=0.89$, ULCI $=1.76$ ). Experiment 3 proved that the mediated role of "Missing amplification effect" between the focusing missing and the happiness experience existed.

In conclusion, the results suggest that focusing missing directly leads to low happiness experience and influence happiness experience by "missing amplification effect” at the same time. In a word, missing is an objective reality, but the missing "black hole” in the mind is the murder who swallowed the happiness experience.

\section{Discussions}

Missing are the more common in people living experience. People often perceive happiness and life are closely related to the gains and missing. The study found that when people have too little (scarcity), attention will have fewer resources section (scarce part) more focused, Causing serious attention resources occupancy, resulting anxiety increased and well-being in decreased (Shah, Mullainathan, \& Shafir, 2012).

In this study, three experiments proved that focusing missing phenomenon was widespread in the happiness experience. And, on the one hand, focusing missing negatively predicts the current experience happiness, on the other hand, focus missing affect happiness experience by deletion amplification intermediary role. So, we thought that focus missing is the leading cause low happiness experience, and missing amplification effect was the psychological mechanisms to explain why the focusing missing lead to the low happy experience. The findings on the one hand the experience of happiness research is an important theoretical contribution, On the other hand how to improve people's well-being experience provides valuable practical guidance.

Focusing illusion theory insists that people will give higher weights at the center events, and overestimate the influence of center events on the whole, ignoring other events. Under the action of focusing illusion, people will give higher weights to easy obtained information (Propper \& Wilson, 2003). The study found that the more missing, the less happiness.

The "missing amplification effect" is the conclusion that people give higher weights at the center events, which has important practical value. The reason that focusing missing leads low well-being is "missing amplification effect”. After finding the root cause, people can guide them to do cognitive reappraisal to their missing, and control missing psychological perception in a reasonable range. Not too much attention to missing part, and appropriate to focus on other positive events. Reducing the missing degree of amplification, the happy experience will be rising.

The study also has many limits needed to improve in the future. Firstly, what is the difference between focusing missing and focusing getting impact happiness experience? Secondly, about the focusing contents, focusing money or focusing affect, which one of the amplification effect is more obvious? Thirdly, whether people at different age will have different influence and character? Finally, the study method could optimize and improve. For example, cognitive neuroscience research techniques, like ERP, Eye tracking, fMRI and so on. These problems will further discuss in the future. 


\section{Conclusion}

In daily life, people will focus on their missing parts, appearing "missing amplification effect”. In addition, "missing amplification effect" is the reason why people have low happiness experience.

\section{References}

Demerouti, E., Bakker, A. B., \& Bulters, A. J. (2004). The Loss Spiral of Work Pressure, Work-Home Interference and Exhaustion: Reciprocal Relations in a Three-Wave Study. Journal of Vocational Behavior, 64, 131-149. http://dx.doi.org/10.1016/S0001-8791(03)00030-7

Diener, E. D., Emmons, R. A., Larsen, R. J., \& Griffin, S. (1985). The Satisfaction with Life Scale. Journal of Personality Assessment, 49, 71-75. http://dx.doi.org/10.1207/s15327752jpa4901_13

Hayes, A. F. (2013). An Introduction to Mediation, Moderation, and Conditional Process Analysis: A Regression-Based Approach. New York: Guilford Press.

Huang, Y. X., \& Luo, Y. J. (2009). Can Negative Stimuli Always Have the Processing Superiority? Acta Psychologica Sinica, 41, 822-831. http://dx.doi.org/10.3724/SP.J.1041.2009.00822

Kahneman, D., \& Tversky, A. (1979). Prospect Theory: An Analysis of Decision under Risk. Econometrica: Journal of the Econometric Society, 47, 263-291. http://dx.doi.org/10.2307/1914185

Kahneman, D., Krueger, A. B., Schkade, D., Schwarz, N., \& Stone, A. A. (2006). Would You Be Happier If You Were Richer? A Focusing Illusion. Science, 312, 1908-1910. http://dx.doi.org/10.1126/science.1129688

Propper, C., \& Wilson, D. (2003). The Use and Usefulness of Performance Measures in the Public Sector. Oxford Review of Economic Policy, 19, 250-267. http://dx.doi.org/10.1093/oxrep/19.2.250

Preacher, K. J., \& Hayes, A. F. (2004). SPSS and SAS Procedures for Estimating Indirect Effects in Simple Mediation Models. Behavior Research Methods, Instruments, \& Computers, 36, 717-731. http://dx.doi.org/10.3758/BF03206553

Rozin, P., \& Royzman, E. B. (2001). Negativity Bias, Negativity Dominance, and Contagion. Personality and Social Psychology Review, 5, 296-320. http://dx.doi.org/10.1207/S15327957PSPR0504 2

Radel, R., \& Clement-Guillotin, C. (2012). Evidence of Motivational Influences in Early Visual Perception: Hunger Modulates Conscious Access. Psychological Science, 23, 232-234. http://dx.doi.org/10.1177/0956797611427920

Schkade, D. A., \& Kahneman, D. (1998). Does Living in California Make People Happy? A Focusing Illusion in Judgments of Life Satisfaction. Psychological Science, 9, 340-346. http://dx.doi.org/10.1111/1467-9280.00066

Sandberg, D. E. (2007). Focusing Illusion: Wealth, Height, and Happiness. Growth, Genetics \& Hormones, 23, 27-28.

Shah, A. K., Mullainathan, S., \& Shafir, E. (2012). Some Consequences of Having Too Little. Science, 338, $682-685$. http://dx.doi.org/10.1126/science.1222426

Wilson, T. D., Wheatley, T., \& Meyers, J. M., (2000). Focalism: A Source of Durability Bias in Affective Forecasting. Journal of Personality and Social Psychology, 78, 821-836. http://dx.doi.org/10.1037/0022-3514.78.5.821 


\section{Appendixes}

\section{Life Satisfaction Scale}

Please read the following topics and select one of the most conform to your own situation.

\begin{tabular}{|c|c|c|c|c|c|c|c|}
\hline Topics & \multicolumn{6}{|c|}{ Disagree } & \multirow{2}{*}{$\begin{array}{r}\text { Agree } \\
7\end{array}$} \\
\hline 1) In the latest week, you experience the happy in most of the time & 1 & 2 & 3 & 4 & 5 & 6 & \\
\hline 2) In the latest week, you experience in most of the time to feel better & 1 & 2 & 3 & 4 & 5 & 6 & 7 \\
\hline 3) In the latest week, you are always very happy laughter & 1 & 2 & 3 & 4 & 5 & 6 & 7 \\
\hline 4) In the latest week, you experience anxiety in the most of the time & 1 & 2 & 3 & 4 & 5 & 6 & 7 \\
\hline 5) In the latest week, you experience the grief in most of the time & 1 & 2 & 3 & 4 & 5 & 6 & 7 \\
\hline 6) In the latest week, you experience the pressure in the most of the time & 1 & 2 & 3 & 4 & 5 & 6 & 7 \\
\hline
\end{tabular}

\section{Gallup Happy Mood Questionnaire}

Please accord to your real opinions or feelings. Don't have to be someone else's opinions, item by item, answer to each of the following statements you agree.

\begin{tabular}{|c|c|c|c|c|c|c|c|}
\hline \multirow{2}{*}{$\begin{array}{l}\text { Topics } \\
\text { 1) If you can live once again, you also would like to live like now }\end{array}$} & \multicolumn{6}{|c|}{ Disagree } & \multirow{2}{*}{$\begin{array}{r}\text { Agree } \\
7\end{array}$} \\
\hline & 1 & 2 & 3 & 4 & 5 & 6 & \\
\hline 2) Your life's situation is very satisfactory & 1 & 2 & 3 & 4 & 5 & 6 & 7 \\
\hline 3) You are happy with your life & 1 & 2 & 3 & 4 & 5 & 6 & 7 \\
\hline 4) So far, you can get the important things you want in life & 1 & 2 & 3 & 4 & 5 & 6 & 7 \\
\hline 5) Your life is roughly in line with your ideal & 1 & 2 & 3 & 4 & 5 & 6 & 7 \\
\hline
\end{tabular}

